\title{
Correction to: Nutrients, vitamins, probiotics and herbal products: an update of their role in urolithogenesis
}

\author{
Renato Nardi Pedro ${ }^{1,2} \cdot$ Asad Ullah Aslam ${ }^{1,3} \cdot$ Rawa Bapir $^{1,9} \cdot$ Jibril Oyekunle Bello ${ }^{1,4} \cdot$ Kamran Hassan Bhatti $^{1,5}$. \\ Joseph Philipraj ${ }^{1,6} \cdot$ Idrissa Sissoko $^{1,7}$. Giovanna Souza Vasconcellos ${ }^{2} \cdot$ Alberto Trinchieri $^{1} \cdot$ Noor Buchholz $^{1,8}$ (i)
}

Published online: 28 April 2020

○) Springer-Verlag GmbH Germany, part of Springer Nature 2020

\section{Correction to: Urolithiasis https://doi.org/10.1007/s00240-020-01182-x}

The original version of this article unfortunately contained a mistake. Rawa Bapir was not listed among the authors. Author group should be:

Renato Nardi Pedro, Asad Ullah Aslam, Rawa Bapir, Jibril Oyekunle Bello, Kamran Hassan Bhatti, Joseph Philipraj, Idrissa Sissoko, Giovanna Souza Vasconcellos, Alberto Trinchieri, Noor Buchholz.

Publisher's Note Springer Nature remains neutral with regard to jurisdictional claims in published maps and institutional affiliations.

The original article can be found online at https://doi.org/10.1007/ s00240-020-01182-x.

\section{Noor Buchholz}

noor.buchholz@gmail.com

1 U-Merge Ltd. (Urology for Emerging Countries), London, UK

2 Division of Urology, Faculdade de Medicina São Leopoldo Mandic de Campinas, Sao Paulo, Brazil

3 Department of Urology, Letterkenny University Hospital, Saolta Healthcare Group, Donegal, Ireland

4 Department of Surgery, University of Ilorin Teaching Hospital, Ilorin, Nigeria

5 Urology Department, Hamad Medical Corporation, Doha, Qatar
6 Department of Urology, Kasturba Medical College, Manipal, Karnataka, India

7 Urology, Faculty of Medicine and Odontostomatology, University of Sciences, Techniques and Technologies, Bamako, Mali

8 Sobeh's Vascular and Medical Center, U-Merge Ltd, Building 73, 3rd floor, Dubai Health Care City, Dubai, United Arab Emirates

9 Department of Urology, Shaheed Shawkat Haji Musheer Hospital, Kurdistan region, Said Sadiq, Iraq 